adaptive radiation, an evolutionary explosion that surpasses in rapidity and extent that of the more widely publicized Galapagos finches or the Hawaiian flycatchers. However, it should not be forgotten that the South American Cichlidae (barely mentioned in this book, and then merely in a zoogeographical context) have played out, almost in counterpoint, an equally intriguing story.

Much of the basic research on cichlid evolution has stemmed from museum and field studies, but there is a body of experimental work which has important bearings on these other researches. A great merit of this book is the way in which its authors have brought together these different aspects, a synthesis that has never been attempted on such a comprehensive scale. Clearly a great deal more of such integrated work remains to be done, and hopefully this book will help to bring together workers in the various disciplines involved. The book's synthetic nature - in the best sense of that word-should at the very least introduce the Cichlidae to a wide circle of students and biologists.

Fryer and Iles attempt to review all aspects of cichlid biology and evolution, and to present them as a coherent whole. The greater part of the book (ten chapters) therefore provides background information on feeding and breeding habits, growth phenomena, synecological studies, genetics, and the morphological features which are basic to our interpretation of these life processes. Finally, all is brought together in three chapters outlining the evolutionary biology of the often perplexing species flocks that dominate the lakes. Other chapters treat the environmental background, the cichlids as a natural resource, and the subject of lake evolution itself.

As a specialist in cichlid fishes myself, I am perhaps the wrong person to judge how well (or badly) Fryer and Iles have presented their subject to a wider audience. I believe they have succeeded. Any author attempting to analyse and review such a vast subject has open to him two possibilities. Either he indulges in gross generalizations or he adopts a seemingly more ponderous, species by species account. Fryer and Iles have chosen the second method. To a nonspecialist the names of numerous taxa may be baffling and a tax on his memory; but if he wants the facts and then the dessert of synthesis, he must work for them. Any other way would not be fair to the subject. The reader's task is somewhat lightened by the illustrations, but what a pity that no colour photographs of the true lake fishes are included (as they are in the American edition which, by the way, is cheaper too!). And why did someone choose as the cover illustration a cichlid (Hemi- chromis bimaculatus) which, even with extreme zoogeographical generosity, can hardly be considered a "Great Lake" species?

In a notice of this length it is impossible to take issue with the authors on the several points where I disagree with their views or interpretations. Some of these disagreements may be almost on the level of family squabbles but there are others of a more general nature, and some should be mentioned.
First there is the section on structure and basic anatomy. This could do with an overhaul and is probably the weakest chapter in the whole book. For example, the figured jaw mechanism (supposedly typical) just does not work; the fish would dislocate its upper jaw every time the mouth was opened (a pity the authors ignored the highly relevant and elegant works of Osse and Liem on this subject).

Clearly Fryer and Iles are fascinated

\title{
Tripod Fish
}

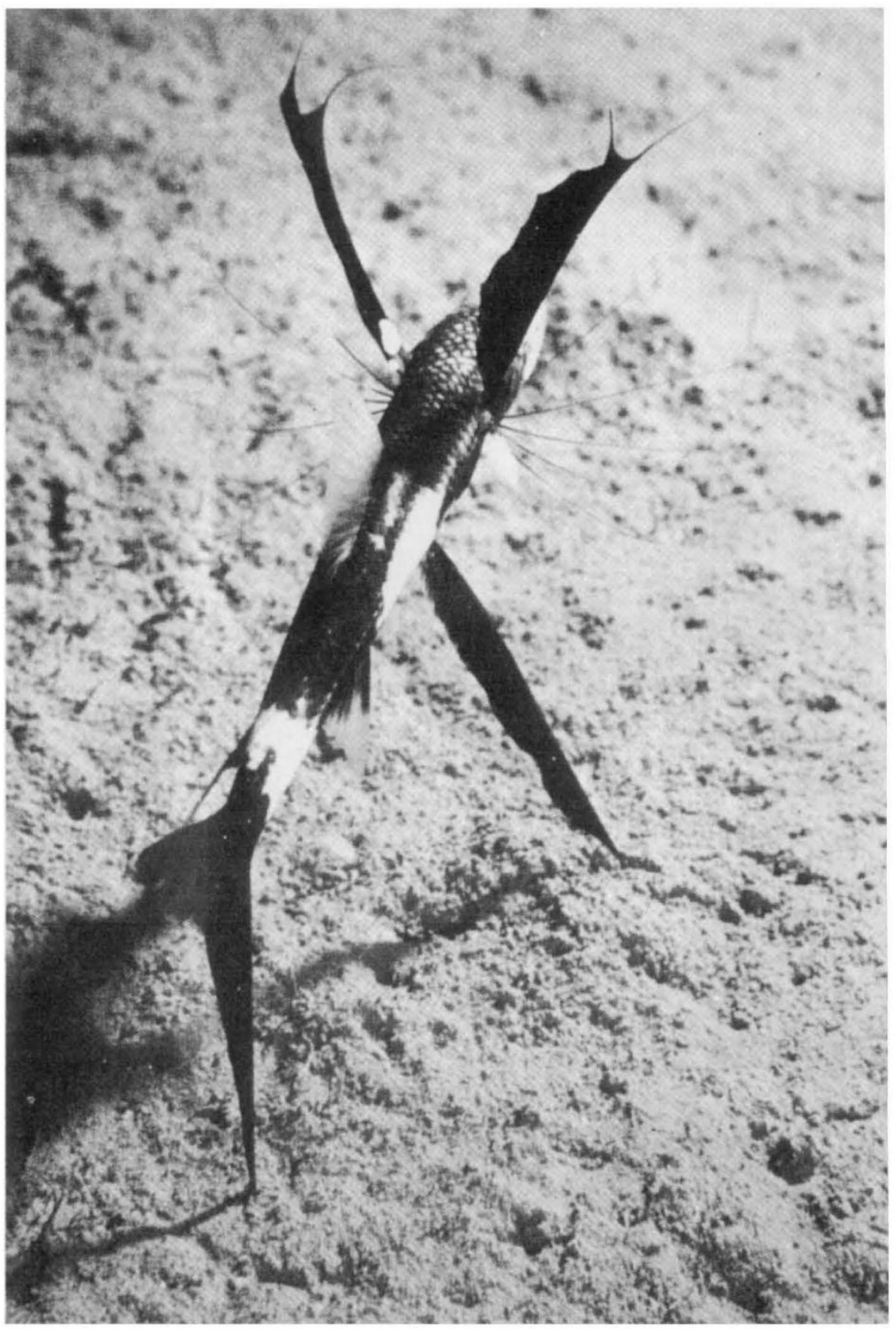

Tripod fish, in ambush facing the current at the bottom of De Soto Canyon in the Gulf of Mexico: a fish which leaves footprints. One of the illustrations in The Face of the Deep, by Bruce C. Heezen and Charles D. Hollister (Oxford University Press, London, 1972). 